Cómo citar este artículo en Chicago: David Solarte, Orlando Enar. "El ser y quehacer de la etnia coreguaje en el saber filosófico ancestral”. Escritos 29, no. 63 (2021): 326-345. doi: http://doi.org/10.18566/escr.v29n63.a08

Fecha de recepción: 17.02 .2021

Fecha de aceptación: 19.08.2021

\title{
El ser y quehacer de la etnia coreguaje en el saber filosófico ancestral ${ }^{1}$
}

\author{
The being and doing of the Coreguaje ethnic group within \\ the ancestral philosophical knowledge
}

Orlando Enar David Solarte ${ }^{2}$

\begin{abstract}
RESUMEN
El existencialismo del ser humano dentro del contexto latinoamericano marca una esencia fundamental desde lo intrínseco y lo extrínseco, para identificar su relación con su otro yo, dentro de la otredad que caracteriza al ser pensante frente a su pensamiento propio. Los coreguaje son una etnia indígena asentada en el departamento del Caquetá que, con su lengua propia, el korebajü (hijos de la tierra), hacen de esta identificación, un eco a su sabiduría de la selva donde, a través de sus costumbres, ritos, lengua y territorio propio, fundamentan las raíces autóctonas de su quehacer, en medio de su cultura. Donarse y entender al otro es uno de sus principios fundamentales para establecer relaciones interpersonales dentro de su hábitat. De igual manera, identificar su saber cósmico y ancestral, punto de partida dentro de los conocimientos de la selva amazónica, hace de esta conceptualización, un erario de la visión cosmogónica que trabajan los ancestros coreguaje; así, sus postulados son ordenados bajo tres concepciones: el Chejaboebü, relación con la naturaleza, el agua, el viento, el trueno, la luna y el sol; el Chejasanaba, relación con el aire y, el Chejasesebü, relación con los astros y las estrellas, posiciones atávicas que forjan un diálogo filosófico manifestado en la oralidad de los saberes propios.
\end{abstract}

Palabras clave: Coreguaje; Existencialismo; Cosmovisión; Latinoamericano; Otredad; Adonado; Fenomenología; Saber filosófico ancestral.

1 El pensamiento humano en la cultura científica, la epistemología como factor clave en la consolidación de la cultura científica e investigativa y la epistemología como fuente del conocimiento.

2 Docente e Investigador, Facultad de Educación, Programa de Ciencias Sociales, Universidad de la Amazonia Florencia, Colombia. Doctorando en Filosofía en la Pontificia Universidad Bolivariana, Colombia. Magíster en Sociología, Atlantic Internacional University EE. UU. Magíster en Etnoliteratura, Universidad de Nariño - San Juan de Pasto, Colombia. Licenciado en Filosofía y Licenciado en Teología, Universidad Mariana - San Juan de Pasto. Correo electrónico: o.david@udla.edu.co. 


\begin{abstract}
The existentialism of the human being within the Latin American context marks a fundamental essence, from the intrinsic and the extrinsic, to identify their relationship with their other self, within the otherness that characterizes the thinking being faced to his own thought. The Coreguaje are an indigenous ethnic group settled in the department of Caquetá, Colombia. With their own language, the Korebajü (children of the earth), and their cultural identity, they make echo of their wisdom of the jungle where the autochthonous roots of their daily work can be found through their customs, their rituals, their language and their own territory. Giving yourself away and understanding the other is one of their fundamental principles to establish interpersonal relationships within their habitat. Similarly, identifying their cosmic and ancestral knowledge, which is the starting point within the knowledge of the Amazon rainforest, makes this conceptualization a treasury of the cosmogonic vision that the Coreguaje ancestors develop. Thus, their postulates can be ordered under three conceptions: the Chejaboebü, the relationship with nature, water, wind, thunder, the moon and the sun; the Chejasanaba, the relationship with the air and, the Chejasesebü, the relationship with the stars, atavistic positions that forge a philosophical dialogue manifested in the orality of their own knowledge.
\end{abstract}

Keywords: Coreguaje; Existentialism; Cosmovision; Latin American; Otherness; Talented; Phenomenology; Ancestral Philosophical Knowledge.

\title{
Introducción
}

La filosofía, a lo largo de su historia, maneja diferentes corrientes de pensamiento que la hacen tomar parte y fuerza en el conocimiento humano. Al descentralizarnos del eurocentrismo, observamos que en América Latina por medio de las culturas indígenas se ha ido gestando una nueva forma de ver al mundo desde diferentes perspectivas, como sus ritos, la medicina ancestral, su manera de concebir la naturaleza, las artesanías, su lengua propia y la familia. Dialogar y filosofar en este contexto es el punto central que desde su génesis se quiere aportar al conocimiento filosófico.

La filosofía ha participado de manera directa en la intervención de los procesos de pensamiento que el ser humano ha generado durante toda su existencia. La relación hombre-espíritu-cosmos ha sido siempre la constante de su devenir conceptual. Desde sus inicios, el gran cuestionamiento del hombre se ha enfocado en el cosmos: ¿cuál es el arjé?, ¿cuál es el principio?, ¿cuál es su origen? Y estos postulados han sido revitalizados paulatinamente, de acuerdo con el proceso histórico. Por su parte, la cosmovisión como fuente de pensamiento para la filosofía, es igualmente un punto relacional importante dentro de la comunidad indígena coreguaje del Caquetá; sus saberes cosmogónicos de la visión del mundo, enfocados en tres niveles: el chejaboebü, el chejasanaba y el chejasesebü, hacen de ellos un grupo predecesor dentro de la sabiduría ancestral. Esta está encaminada, con sus chamanes y caciques, a irrigar a todos sus miembros el conocimiento gracias a la oralidad, y así formar un diálogo epistemológico, punto fundamental para descubrir su esencia: donarse hacia el otro, para reflejar la manifestación de la comunidad a lo largo de la historia.

Los coreguajes son una etnia indígena ubicada en varios caseríos a lo largo de los ríos Orteguaza y Caquetá y sus afluentes, en el sudeste de Florencia, Caquetá. Su lengua propia es el korebajü, que significa "hijos de la tierra”. Con esta identificación, hacen un eco a su sabiduría de la selva donde, con sus costumbres, ritos, lengua y territorio propio, fundamentan las raíces autóctonas de su quehacer en medio de su cultura. La agricultura es su fuente principal de supervivencia y, en menor medida, la caza y la pesca. 
Su unidad básica de parentesco es la familia nuclear y conservan la importancia de la familia extensa ${ }^{3}$. Históricamente, los coreguajes se han visto implicados en procesos políticos, sociales y culturales que han alterado su modo de viva. Uno de ellos tiene que ver con la explotación de la quina y el caucho, que ocasionó una considerable pérdida demográfica, dado el maltrato de los caucheros, quienes aprovechaban su mano de obra y se apropiaban de grandes extensiones de tierra para la ganadería.

Las misiones evangelizadoras de franciscanos y capuchinos también tuvieron mucho que ver en la disminución de su lengua nativa y los cambios en su organización social (figura 1). ${ }^{4}$

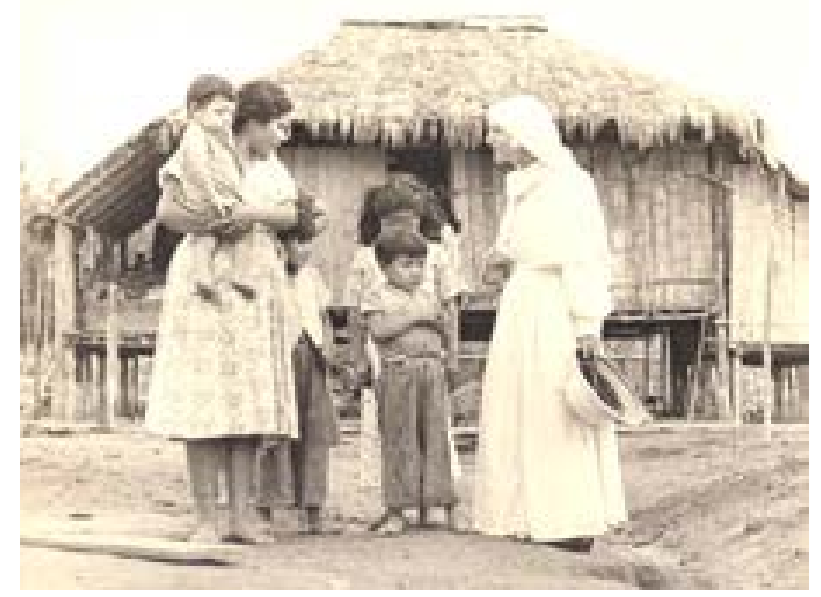

Figura 1. Monja en misión evangelizadora ${ }^{5}$

Estos procesos trajeron como consecuencia un contacto más directo de los indígenas con los colonos, pero en condiciones de desigualdad por las constantes amenazas a sus reservas territoriales y a su cultura. Posteriormente, el narcotráfico y los problemas de orden público pasaron a ser factores adicionales a la presión sobre ellos como comunidad. No obstante, merced a sus esfuerzos organizativos y a la defensa de su cultura, hoy día se hace un reconocimiento de sus derechos humanos, "consolidados en la Constitución Política de 1991 y en diversos instrumentos nacionales e internacionales, los cuales ayudan a cimentar los procesos de resistencia comunitaria que a lo largo de su historia y aún hoy continúan forjando". ${ }^{6}$

3 Ministerio de Cultura, "Caracterizaciones de los pueblos indígenas de Colombia", acceso el 31 de octubre de 2021, https://www.mincultura.gov.co/prensa/noticias/Documents/Poblaciones/PUEBLO\%20KOREGUAJE.pdf.

4 Ministerio de Cultura, "Caracterizaciones de los pueblos indígenas en riesgo", acceso el 31 de octubre de 2021, https://www.mincultura.gov.co/areas/poblaciones/pueblos-indigenas/Documents/Compilado\%20de\%20 Caracterizaciones\%20Pueblos\%20en\%20Riesgo.pdf.

5 Morales Escobar, Paola Inés. "Comunicación y cultura en la selva: La comunidad coreguaje". Tesis de grado. Pontificia Universidad Javeriana, 2008. https://repository.javeriana.edu.co/bitstream/handle/10554/5330/tesis315. pdf?sequence $=3$.

6 Ministerio de Cultura, "Caracterizaciones de los pueblos indígenas de Colombia", acceso el 31 de octubre de 2021, https://www.mincultura.gov.co/prensa/noticias/Documents/Poblaciones/PUEBLO\%20KOREGUAJE.pdf. 
“Antes de esta violencia que se ensañó con los indígenas de la Amazonía, los pueblos indígenas coreguaje siempre fueron sinónimo de riqueza cultural y natural"?

Bajo este entendimiento, se desprende una pregunta central para ubicar al lector en lo que se pretende alcanzar con este artículo: ¿es posible plantear un diálogo epistemológico entre la cosmovisión coreguaje y la filosofía occidental? Pregunta que, a su vez, da pie a formular los siguientes interrogantes secundarios:

- ¿Cuál es la sabiduría oral de la cosmovisión ancestral coreguaje frente a la madre tierra?

- ¿Cuáles son las categorías específicas en la cosmovisión de los coreguajes?

- ¿Cómo realizar un diálogo con la filosofía occidental a través de la cosmovisión ancestral coreguaje?

Nuestros ancestros desde su sabiduría propia han abordado un camino silencioso y, en muchas ocasiones oculto, ya que sus vivencias y tradiciones en un conocimiento casi hermético no han florecido en el aporte científico y filosófico. Investigar y adentrarse en una cultura indígena amazónica como la de los coreguajes, que no es opuesta pero sí sigilosa frente al mundo exterior de la tecnología y la cientificidad, hace de esta investigación un punto de referencia para dialogar con nuestros ancestros en medio de la madre tierra, y este es un punto primordial: filosofar con la naturaleza, pensar en el cantar de los pájaros y los ríos, dialogar con el arte rupestre, experimentar por medio de la medicina tradicional como un nuevo avatar dentro del conocimiento hacen de este encuentro un nuevo frente hacia el encuentro con el saber ético, político y filosófico; orquestar y dialogar filosóficamente desde la sabiduría coreguaje en el contexto actual de la discusión filosófica occidental es un entramado que ahondará el saber amazónico.

Así, con este trabajo, no se pretende profundizar en puntos concretos como la lingüística, la organización social y política, sino hacer una descripción detallada de las prácticas culturales reflejadas en la interacción de los miembros de esta comunidad, sus labores diarias, sus roles sociales, las artesanías, los conocimientos de la selva y la utilización de sus recursos.

Es solo dar a conocer esa violencia que han sufrido los coreguajes y que ha impedido que las personas vean su cultura, su política, la sociedad que conforman, sus prácticas sociales, su trabajo material y la transmisión del conocimiento, para empezar a ver una comunidad que debe ser estudiada y analizada desde distintos ángulos y áreas del conocimiento, en el mismo lugar donde se reproducen, se construyen, se encuentran y se reconstruyen; un lugar donde la palabra, el trabajo material, las situaciones sociales y la política representan a la mayoría "en la creación y consolidación de la cultura y la sociedad".

En 2009, el pueblo coreguaje es reconocido por la Corte Constitucional en el Auto 4 de 2009 proferido en seguimiento a la Sentencia T-025/04 como un pueblo indígena en riesgo de extinción física y cultural, con lo cual se fortalecen los esfuerzos institucionales para su protección como los procesos organizativos en todas las comunidades según su plan de vida, encaminados a la construcción de un plan de salvaguarda que garantice la pervivencia de este pueblo. ${ }^{9}$

7 Andrés Romero López y Ángela Patricia Muñoz, Caracterización pueblo indígena coreguaje (Bogotá: Procuraduría General de la Nación, 2019), 6, https://www.procuraduria.gov.co/portal/media/file/Caracterizacion\%20Coreguaje.pdf.

8 Morales, "Comunicación y cultura en la selva", 26.

9 Ministerio de Cultura, "Caracterizaciones de los pueblos indígenas de Colombia", acceso el 31 de octubre de 2021, https://www.mincultura.gov.co/prensa/noticias/Documents/Poblaciones/PUEBLO\%20KOREGUAJE.pdf. 
La cosmovisión entre los coreguajes, que es transmitida con intermediación de la oralidad, es un aspecto interesante entre sus creencias, ya que estos saberes ancestrales son los que delimitan su posición frente a la naturaleza. Para ellos, la naturaleza es un todo frente al hombre; ella es la que guía para continuar como pueblo; es la madre que da la vida. Según su cosmovisión, el mundo posee tres niveles: el chejaboebü, que es la tierra de abajo; es el nivel donde habitan las personas y poseen la relación directa con la naturaleza, el viento, el agua, el trueno, la luna y el sol; el chejasanaba, que es la tierra del centro donde se encuentra el aire; es un lugar propio de los sabedores o chamanes, y, por último, se halla el chejasesebü, la tierra de los astros y las estrellas, donde no hay seres humanos.

Estos antecedentes que revitalizan la etnia coreguaje son el punto de partida para realizar un diálogo epistemológico, punto focal para interpretar esta realidad ancestral mediante la reflexión y disertación de pensadores que, con posiciones éticas y políticas, marcan un vestigio en el conocimiento filosófico.

En el estado actual, podemos darnos cuenta de que observar y describir los diferentes trabajos que se han llevado a cabo sobre la etnia coreguaje implica una búsqueda minuciosa, dado que son pocos los estudios que se han hecho en torno a ellos como comunidad indígena amazónica. En este sentido, Prada ${ }^{10}$ deja ver la valentía y el coraje que han caracterizado a esta etnia; el éxodo de su tierra propia, en busca de aposentos diferentes de los suyos para lograr salvar sus vidas de la guerra, una guerra que no ha sido suya, pero que, indirectamente, los ha obligado a vivirla en carne propia. La autora narra la historia de cómo un pájaro metálico de matrícula HK-388 originó un episodio de violencia con las antiguas guerrillas denominadas en su tiempo M-19. La aeronave, que fue secuestrada en La Guajira cuyo destino era alimentar el arsenal de guerra de este grupo armado, introdujo en su cultura el carácter bélico de la guerra; muchos de los nativos fueron obligados a pertenecer a dicho grupo y, por ende, a perder la insignia de su cultura.

Al llegar el proceso de paz con este grupo guerrillero, penetra otro con más ahínco y proceder guerrerista: las llamadas Fuerzas Armadas Revolucionarias de Colombia-Ejército del Pueblo (FARC-EP). Su accionar fue más belicista; empezaron a caer grandes líderes indígenas coreguajes; sus normas e imposiciones eran claras y quien no las cumpliera tenía dos caminos: desalojar su territorio y pagar con su vida, sin importar su accionar. Poco a poco, obligaron a este grupo étnico a perder sus tradiciones, ya que el narcotráfico y la guerra se habían apoderado de la región, y el glifosato (por parte del Gobierno en su afán de erradicar los cultivos de coca) afectó su producción agrícola.

En este episodio de la historia coreguaje, Piranga recuerda:

Nos arrebataron nuestros líderes, creencias y vidas, pero no nos quitarán el sentir indígena y el amor por la selva, nuestra tierra. Hoy caminamos el territorio para perdonar y encontrar de nuevo la armonía.

Banisookaisiname mai ainare, mai kuasache name paivanare, jatani mai paichetani siamamu, pojuju mai pai chejare kuirame. Irumu nukakuime mai cheja kuasa oiju kabesuuñu chiini, mama pai jachere jñaañu chinnì. ${ }^{11}$

10 Edilma Prada, "Coreguaje: Voces de un despojo", en Memorias: 12 historias que nos deja la guerra (Bogotá: Konrad Adenauer Stiftung, 2017), 173-192. http://consejoderedaccion.org/webs/memorias12historias/-.

11 Prada, “Coreguaje", 173. 
Jiménez, ${ }^{12}$ por su parte, narra las creencias avaladas por miembros de la comunidad indígena coreguaje: el makatañu, o duende, que, según la tradición, es el dueño de la selva y todo lo que ella contiene; el chondú, otra manifestación de la creencia ancestral, raíz o planta que se manifiesta a la hora de la pesca, al ser mascada por el pescador; su uso actual, según la tradición, sirve para enamorar y hacer el mal. Otro contexto manejado por Jiménez son los diferentes nombres que se les da a los animales de la selva y su significado en la etnia coreguaje, que representan el beneficio o las consecuencias que ellos acarrean en su trasegar.

De igual manera, los diferentes mitos y leyendas en relación con el ser humano y su conexión con su hábitat natural, que narran diferentes informantes, como los llama Jiménez en sus relatos; Naso Cano, Romio Wesico, Ño Kuta Sence y Waticaa, como mitos y leyendas de referencia. Jiménez continúa desarrollando una serie de narraciones e historias que proporcionan diferentes informantes, en cada una de las cuales hacen uso de su palabra, para llevar a cabo el discurso narrativo y, por ende, contar una historia propia que se vive o se ha vivido en la comunidad indígena coreguaje.

Morales, ${ }^{13}$ por otro lado, enfatiza en algunos aspectos importantes: el contexto de los coreguajes, su historia, su economía, su aspecto político, social y religioso, y su cultura actual, a partir de los diferentes episodios vivenciales a lo largo del tiempo y de cómo esta cultura ha logrado rescatar su vestigio ancestral, tradicional y cultural: el canto, la danza, la pintura, los matrimonios, la chicha, el yagé y su lengua. También trabaja un punto importante: la comunicación, la cultura y el mundo simbólico, mediante entrevistas a diferentes personalidades y lleva a cabo un análisis sobre diferentes temas relacionados con lo simbólico que, arduamente, potencializa el saber ancestral por medio de la oralidad.

Ahora bien, como el objetivo principal era investigar la cosmovisión ancestral de los coreguajes y tener la posibilidad de un diálogo epistemológico para comprender la filosofía por medio de la oralidad, también había que analizar la sabiduría oral de su cosmovisión ancestral frente a la madre tierra, identificar las categorías específicas en su cosmovisión y realizar, a través de esta, un diálogo epistemológico en torno a la filosofía.

\section{Metodología}

El modelo de investigación es cualitativo, paradigma que se propone estudiar un problema investigativo desde diferentes aspectos a partir de una realidad determinada; en este caso, el estudio que se aborda en su contexto es la relación que posee la cosmovisión ancestral de los coreguajes como un diálogo epistemológico para comprender la filosofía mediante la oralidad.

Este trabajo, que parte de una hipótesis respecto del objeto de estudio, es el ejercicio sólido que se desea expresar por medio de un análisis en su desarrollo. El problema que se plantea surge a partir de razonamientos e inquietudes realizados gracias a un ejercicio académico y experiencial del papel que representa la cosmovisión ancestral coreguaje en un diálogo epistemológico y filosófico. Cabe mencionar

12 Margarita Jiménez, Tradiciones coreguaje (Quito: Abya-Yala, 1989).

13 Morales, "Comunicación y cultura en la selva". 
que dicho ejercicio cognoscitivo es un proceso que, paulatinamente, se debe ahondar y profundizar por medio de estrategias metodológicas y conceptuales, y así brindar a la comunidad académica una solución a la pregunta orientadora que se ha propuesto para esta investigación.

Así, este estudio se propone y aspira a interpretar acciones a partir de contextos singulares, es decir, con los agentes o las muestras representativas con que se trabajará empleando conversatorios y entrevistas. Entendido de esta forma, es importante reconocer el contexto, los significados y las particularidades para que, a partir de esta perspectiva, se puedan orientar y reestructurar los procesos que se pretende desarrollar en los objetivos tanto general como específicos.

En este sentido, el estudio permitirá definir ciertas categorías que, a partir de los objetivos específicos, ayudarán a condensar lo que se desea investigar. Las categorías definidas en el contexto y que serán desarrolladas, tales como la cosmovisión, la oralidad, la epistemología y la filosofía, son los quehaceres académicos y de trabajo que permitirán visualizar y obtener datos consecutivos y coherentes con lo propuesto en la formulación de la pregunta.

Posteriormente, un papel importante en el trabajo investigativo es la interpretación de los resultados que surgen a partir de las categorías y al mismo tiempo su descripción, momento esencial para clasificar los diferentes datos que arrojen los conversatorios. Para validar las interpretaciones del investigador y buscar ampliarlas, se harán entrevistas semiestructuradas con los sabedores o chamanes, caciques, líderes y comunidad indígena coreguaje, y se registrarán los comentarios para elaborar ese diálogo epistemológico.

El enfoque investigativo es el histórico-hermenéutico, ya que es el más apropiado para lograr alcanzar los objetivos trazados dentro del estudio. Así, el investigador que lidera esta propuesta se propone por medio del recorrido investigativo efectuar una lectura crítica de la realidad en cuanto a la cosmovisión ancestral de los coreguajes y, al mismo tiempo, indagar el diálogo epistemológico y filosófico frente a su propia oralidad. Por tanto, a partir de este momento, se hace una descripción e interpretación de la situación problémica que se presenta en el contexto a estudiar para luego comprender las prácticas sociales y sus interacciones en la filosofía.

Además, se ha seleccionado este enfoque, puesto que:

- Define categorías que se constituyen en unidades de análisis y orientan todo el proceso investigativo.

- Considera el conocimiento cotidiano de los grupos sociales que, en este caso, es la comunidad indígena coreguaje.

- Su ejecución proyecta efectos transformadores en el contexto en que se desarrolla.

- Se encamina a reflexionar sobre el problema del cosmos desde el saber propio de los coreguajes.

El tipo de investigación que se ha desarrollado ha sido el etnográfico, puesto que con la ayuda de él se ha logrado describir el tipo de investigación que se va a utilizar. En este sentido, es necesario apreciar dos términos como etnología y la etnografía, que, desde una visión antropológica y desde una realidad social investigativa, adquieren un sentido bien definido. Por una parte, el primer término, según Geertz, ${ }^{14}$ suele ser definido como la disciplina que se ocupa de describir o reconstruir los escenarios de diferentes

14 Clifford Geertz, La interpretación de las culturas (Barcelona: Gedisa, 1987). 
grupos o pueblos, mientras que la etnografía tiene que ver directamente con el trabajo de campo, sobre el terreno y con la recogida de información y de materiales. En cuanto al trabajo de campo, Geertz señala que "el lugar de estudio no es el objeto de estudio" ${ }^{15}$ diferenciando en una acción investigativa el campo del objeto estudiado.

A partir de estos supuestos, el método etnográfico permite estudiar diferentes sociedades o grupos definidos. Para el trabajo, es evidente determinar nuestro grupo social y, para ello, se trabajará con una población que en este caso son los indígenas coreguajes del Caquetá.

La población y muestra del estudio se forma de la unidad de análisis y la unidad de trabajo, que es la comunidad indígena coreguaje del Caquetá. Para ello, se llevan a cabo unos criterios de inclusión, entre ellos que haya disponibilidad de tiempo, que sea un individuo que pertenezca a la comunidad indígena objeto de estudio y que haya interés por la investigación propuesta.

Entre las técnicas de investigación se considera la entrevista como herramienta de interacción social. La base fundamental de este proceso radica en la formulación de preguntas por el investigador en que, a partir de las alocuciones por parte de los sujetos investigados, toma atenta nota frente a las respuestas que emitan los participantes, para luego detallar el camino siguiente, que es la recolección de la información. En este sentido, de acuerdo con Sabino, "se establece un diálogo peculiar, asimétrico, donde una de las partes busca recoger informaciones y la otra se nos presenta como fuente de las informaciones". ${ }^{16}$

El conversatorio también es una técnica que genera muchas ideas en un grupo y requiere la participación espontánea de todos. En este espacio, los participantes toman algunos temas coyunturales, entendidos como altamente significativos en el momento específico en que se ofrece la enseñanza. No es una conferencia (que requiere preparación y diseño de material de apoyo) dictada por un especialista que, incluso, puede ser un experto en el manejo de los medios. La mayoría de las veces, en esta estrategia pedagógica, el invitado es una persona con una gran experiencia sobre el tema objeto de la convocatoria, que ilustra el manejo, el desarrollo o los últimos avances de un saber.

\section{Resultados y discusión}

\section{Los coreguajes y el ser en su cultura amazónica}

El Amazonas es una de las regiones prominentes y preponderantes en la geografía suramericana; su naturaleza, su fauna, su vegetación, su hidrografía y su climatología, que son núcleos importantes en su contexto territorial, hacen de este asentamiento un lugar exuberante e importante para el globo terráqueo. La Amazonía en la geografía colombiana posee en su estructura político-administrativa ocho departamentos; uno de ellos es Caquetá, donde reside desde tiempos antiquísimos esta comunidad indígena.

15 Geertz, La interpretación de las culturas, 33.

16 Carlos Sabino, El proceso de investigación (Buenos Aires: El Cid, 1976), 174-75. 
Los coreguajes conforman una cultura étnica indígena nativa en el Caquetá y es uno de los grupos tucano-occidentales más numeroso, sin olvidar las demás culturas indígenas que han migrado desde otros departamentos hacia este territorio. Su lengua autóctona es el korebajü que significa "hijos de la tierra”. Asimismo, poseen una organización social, política, económica y religiosa. Según Piranga, citado en Prada ${ }^{17}$ se estima que actualmente existen 2012 indígenas coreguajes distribuidos en dos municipios: Solano y Milán, con 18865 hectáreas. La supervivencia se concentra en la agricultura, la pesca, la caza, la cría de animales y la elaboración de artesanías.

Estos antecedentes, que revitalizan la etnia coreguaje, son el punto de partida para realizar un diálogo filosófico, punto focal para interpretar la realidad ancestral mediante la reflexión y la disertación que, a través de posiciones éticas y políticas, marcan un vestigio en el conocimiento filosófico. En este sentido, se contextualiza la esencia para dialogar con el saber ancestral coreguaje en su cosmovisión propia, autóctona y original.

Una de las preocupaciones de la filosofía en la historia del pensamiento ha sido el problema de la cosmovisión y, para resolverlo, han sido implementadas categorías importantes para descifrar el problema del mundo. Desde la filosofía, observamos que diferentes pensadores han realizado e indagado acercamientos en relación con el mundo: ¿de dónde viene? y ¿cuál es el origen? son los interrogantes que han estado presentes en la filosofía, y así su itinerario epistemológico ha suscitado respuestas que han marcado la existencia del ser humano para organizar ideas propias en una estructura de pensamiento.

En este sentido, la etnia coreguaje, como cultura indígena perteneciente a la Amazonía, está demarcada por un giro cosmogónico animista que se da en relación con los animales como un intercambio o una conversación; y ellos, en un sentido estricto, forman parte de ese otro que está a mi lado en un hábitat que nos pertenece; en esta óptica, yo no puedo ser la negación de mí propio yo, y tampoco puedo negar al otro que se encuentra respecto de mi estado natural. En la selva, yo soy el producto de ese otro que, por más que lo aleje, se manifiesta en el hecho de una sabiduría propia para algunos y necesaria para otros. Maritain, citado por Díaz, sostuvo: "Por el mero hecho de ser yo una persona y de comunicarme a mí mismo, exijo comunicarme con el otro, y con los otros, en el orden del conocimiento y del amor”. ${ }^{18}$

\section{El adonado y el otro, otra forma de ser}

La visión de ser humano desde un enfoque latinoamericano y el mundo en el cual habita designa a las culturas indígenas y, en este caso, a la etnia coreguaje como sujetos que, en primera instancia, viven para sí; es decir, su perspectiva antropológica se relaciona consigo mismos para poder entender su propio yo y, a partir de estas consecuencias de la reflexión con ese "yo", tratan de entender su entorno y el mundo que los rodea. Bajo este entendimiento, ese "yo" se comporta como el sujeto que piensa, vive, siente, respira; en fin, es un todo para sí mismo.

El "yo pienso" no basta para descubrir la fenomenicidad de lo que no puede ya reconocerse como un sujeto y él recibe lo mismo de lo que da. Incluso, en una situación tan radicalmente metafísica como la

17 Prada, "Coreguaje".

18 Arturo Díaz, "La concepción de la persona en Jacques Maritain: Desde la noción de individuo a la de libertad personal”, Polis: Revista Latinoamericana 15 (2006): 28. https://journals.openedition.org/polis/4874. 
de Kant o Descartes, cuando la llamada se lleva a cabo para mantener su persona, el yo debe desaparecer y dejar el campo al adonado; sin duda, nuestro resultado no se consigue sin una cierta violencia en la lectura; pero la violencia no consiste más que en tomar en serio los indicios que en los textos teóricos canónicos del sujeto demuestren que este no puede reducirse al "yo me pienso", ni a su propia igualdad consigo mismo: yo = yo. Antes de la consciencia de sí, se trata del hecho consumado a posteriori de la llamada dada a priori, de la eventual respuesta a su sorpresa: interpelado, el sujeto sabe de entrada que solo se encontrará en lo que se da, en tanto se da él mismo. Desde ese momento, hay que avanzar, pues, más allá de los esbozos que, "a la manera de síntomas, la fenomenología real y la metafísica han trazado, a pesar de ellas, para describir ahora directamente el adonado en cuanto tal, como aquel que se recibe el mismo de lo que se da". ${ }^{19}$

Para desmitificar ese orden de libertad y adonado, se tendría que puntualizar un recorrido hasta la comunidad coreguaje, que es lo que se hará más adelante, para dar continuidad al estudio investigativo que se ha propuesto. Por lo pronto, debemos entender que apropiarse de sí, de su interior, sugiere un apartarse del sujeto para "adonarse" al otro; ese otro que mira, observa y reflexiona en torno a lo que significa el propio ser frente a una realidad determinada; sin el otro, no se puede co-existir; se necesita del otro para apropiarse del "yo" igual a "yo", lo que realmente no significa egocentrismo, sino más bien entender la propia autenticidad, para pensar con el otro y por el otro.

Estos argumentos ponen de manifiesto un decir frente a una realidad determinada; en otras palabras, el "yo" se debe poner en el lugar del otro, sin esperar nada a cambio. Un interés debe convertirse en un desinterés para formar una alteridad, y cuando el ser humano forma parte de esta tríada, se puede afirmar que nace la filosofía del amor; por eso, lo que define al ser humano no es el ser, el interés, sino, por el contrario, es el desinterés con el que me enfrento al otro.

Según Lévinas, citado por Giménez Giubbani, ${ }^{20}$ un humanismo que me lleve al otro, una responsabilidad en torno al otro, para responder totalmente por el otro. Es, por momentos, difícil entender estos supuestos; una persona no puede seguir su autoridad existencial con un yo cerrado, también debe convertirse en un yo abierto, desinteresado. En este sentido, la filosofía es un pensar en el otro y no en el yo; es un acercarse al otro, para vivir la otredad que, según el poeta rumano Paul Celan, citado por Valle, sería: "yo soy tú, cuando yo soy yo". ${ }^{21}$

La otredad es el vínculo que une al ser humano en verdadera autenticidad, en busca del bien del otro y, si se puede afirmar, con un antagonismo severo, por qué no, el bien del enemigo. El otro representa la presencia de un ser que no entra en las esferas de él mismo; por el contrario, él entra a formar parte de ese otro que no es él; por eso, él responde a aquello que no es la persona, aquello que no es anterior a esa persona. El otro le afecta y le importa, es decir, la persona no puede guardar distancia con el otro; como sujeto, está llamado a responder por el otro, en otras palabras, aquí ella queda sustituida por el otro. Sin ser permisivos o celestinos, el "yo" tiene que acoger al "otro" como un infinito, como un trascendente,

19 Jean-Luc Marion, Siendo dado: Ensayo para una fenomenología de la donación (Madrid: Síntesis, 2008$), 444$.

20 Analía Giménez Giubbani, "Emmanuel Lévinas: Humanismo del rostro”, Escritos 19, n. o 43 (2011): 337-349. https:// revistas.upb.edu.co/index.php/escritos/article/view/6718.

21 José Miguel Valle, "Yo soy tú, cuando yo soy yo", Espacio Suma NO Cero, acceso el 31 de octubre de 2021, https:// espaciosumanocero.blogspot.com/2020/04/yo-soy-tu-cuando-yo-soy-yo.html. 
ya que el otro forma parte de una realidad en un contexto determinado con la sociedad, con el mundo y con la infinitud; aun así, es un deber responsabilizarse de las necesidades del otro, ya que, filosóficamente hablando, el propio punto de partida no ha de ser el propio conocimiento, sino el reconocimiento del otro; a través del otro, se ve a sí mismo. En este sentido, el otro constituye el propio yo. Para Lévinas, el otro es el otro: "El Otro en tanto que otro, tal y como se expresó antes, se sitúa en una dimensión de altura y de abatimiento - glorioso abatimiento-; tiene la cara del pobre, del extranjero, de la viuda y del huérfano $y$, a la vez, del señor llamado a investir y a justificar mi libertad. ${ }^{22}$

Según estos parámetros, el otro no es ese ente lejano, inequívoco, adverso; más bien, es el otro, que forma parte de mi colectividad en torno a mi quehacer cotidiano; yo = yo puede ser veraz con un yo = otro; esto es, el otro forma parte de mi ser dentro de una sociedad determinada. Yo soy en relación con el prójimo, es el uno para el otro, a partir del otro soy yo; como consecuencia, mi responsabilidad se sitúa en relación con el otro; no hay infinito sin responsabilidad.

Es en la responsabilidad por el otro hombre de donde surge mi propia unicidad. Esa responsabilidad no podría delegársela a nadie. La obediencia al Altísimo significa, precisamente, esta imposibilidad de esconderme, de escapar. Es esa imposibilidad lo que me vuelve único. "Ser libre, es hacer solamente lo que nadie puede hacer en mi lugar. Obedecer al Altísimo, es ser libre". 23

Esa libertad que me conduce a realizar actos y a pensar en relación con el otro es el hecho que despliega la relación profunda en el contexto sociológico de lo humano; la experiencia con el otro es la apropiación de una realidad que indirectamente no es mía; sin embargo, el hecho de ser humano es la alteridad que me lleva a pensar en ese otro que se manifiesta por medio de su otredad. El otro es exterior a mí, sin medidas, sin distancias y se acerca a mí, manteniendo una relación ética, en que la exterioridad de ese otro me obliga a pensar en su rostro que anima el infinito de mi quehacer cotidiano.

La relación yo $=$ otro es inminentemente necesaria para construir y deconstruir; es necesario que exista una complementación para abordar el andamiaje que debe bordear la existencia del ser humano, de lo demasiadamente humano. En este contexto, Lévinas ofrece una filosofía grande y robusta, la cual debe dejarse animar por el otro, en un sentido estricto pero flexible, en que la comunicación de la consciencia de sí, el ser de sí y el ser en sí sean los artífices del nuevo conocimiento que vaya en pro de una alteridad correlacional entre el yo y el tú.

El yo o el sí mismo, que parecería ser su sujeto o su condición, el sí que toma la figura de un ente entre los entes, verdaderamente quedaría reducido a una abstracción descontada sobre el proceso concreto de la consciencia de sí o la "ostención" del ser en la historia o en el estiramiento del tiempo, en que el ser se muestra a sí mismo por medio de rupturas y reencuentros. ${ }^{24}$

La consciencia de sí en el ser es esa acción que me lleva al encuentro con mi propio ser, sin olvidar la consciencia de sí del otro. Aquí se debe manejar una correlación entre los dos artífices; debe existir un

22 Emmanuel Lévinas, Totalidad e infinito: Ensayo sobre la exterioridad (Madrid: Sígueme, 1977).

23 Emmanuel Lévinas, Más allá del versículo: Lecturas y discursos talmúdicos (Buenos Aires: Lilmod, 2006), 107.

24 Lévinas, Totalidad e infinito. 
entrelazado experiencial entre el yo y el otro. El otro lleva a pensar en la otra persona en una relación profunda de la experiencia existencial, expresión de nuestra interioridad propia o ajena. Esa consciencia de sí es el pensamiento del logos que me conduce a observar el infinito en el camino; el gozo de esa consciencia de sí, automáticamente, debe relacionarse con sus propios dones, con la confianza en sí mismo observando mi propia interioridad; es decir, mirar la cosas que tengo dentro y, en este sentido, cuando me hago responsable del otro, es cuando me vuelvo más infinito.

El infinito es, como consecuencia, un paso que desde lo terrenal se prepara para llegar a su encuentro; por consiguiente, este paso adquiere sentido cuando el cuerpo, ya cansado de existir en el mundo, ve en el infinito su camino, hecho que solo se marca con la muerte, separación material del yo = otro, paso obligatorio para todo ente que habita el planeta Tierra.

La muerte del otro que muere me afecta en mi propia identidad como responsable; el hecho de que me vea afectado por la muerte del otro constituye mi relación con su muerte. La muerte es partida, deceso, negatividad, cuyo destino se desconoce. La muerte es la mortalidad exigida por la duración del tiempo. ${ }^{25}$

\section{El ser y el quehacer latinoamericano desde Sartre}

El pensamiento latinoamericano, a lo largo de décadas, desea encontrar un norte en su amplitud libertaria frente a su esencia y filosofía propia. Ser latinoamericano refleja el impacto que el ente pensante debe poner en medio de una sociedad ávida de irrigación intelectual frente a su propio mundo, marcando una ideología que la identifique como tal. Ser latinoamericano es encontrar la libertad que lo hace a sí mismo un humano con responsabilidad sobre su vida. Ser latinoamericano es vivir un existencialismo que implique desmitificar la verdad en la vida humana y, entonces, "lo que podemos decir desde el principio es que entendemos por existencialismo una doctrina que hace posible la vida humana y que, por otra parte, declara que toda verdad y toda acción implican un medio y una subjetividad humana". ${ }^{26}$

Sartre es puntual en sus afirmaciones, ya que indaga al ser humano para enfocar en su vida humana un eslabón para encontrar una acción frente a una elección que el ser humano debe realizar en torno a su capacidad creadora y pensante. La libertad frente a una elección es una posición que una persona con carácter latinoamericano está decidida a transitar y, en muchas ocasiones, puede que el camino no sea el mejor; existirán escollos, censuras, inconformismos y tal vez desplazamientos.

Si mi elección está tomada, mi verdadero camino es seguir, en busca del fin y su verdad indescifrable. Este fetiche libertario de grito frente a mi esencia de verdadero latinoamericano es un contexto que no puedo desligar del pensar ancestral e indigenista. Soy la evolución de un pasado que crea en mí una angustia aislada y desamparada, como la aprehensión existencial de mi libertad frente a mi quehacer latinoamericano y grito al mundo: "el desamparo implica que elijamos nosotros mismos nuestro ser. El desamparo va acompañado de la angustia", 27 cuando se tiene que decidir y elegir un camino y él está demarcado en un acontecimiento profundo que entrelaza la libertad frente al ser del primigenio

25 Gabriela Flores, "La muerte desde Lévinas", Alpexistencial, acceso el 31 de octubre de 2021, https://www.alpexistencial. com/post/la-muerte-desde-lévinas.

26 Jean-Paul Sartre, El existencialismo es un humanismo, trad. por Victoria Prati (Barcelona: Edhasa, 1973 ), 9.

27 Sartre, El existencialismo es un humanismo, 23. 
indigenista que atraviesa el sentir latinoamericano. El ser humano está marcado desde su ser colectivo a ser libre y esa libertad, según Sartre, es obtener una responsabilidad que se adueña de su ser que, desde un contexto latinoamericano indigenista, es la que se enmarca en la naturaleza salvaje que, por momentos, ocasiona angustia; pero tales hechos llevan a encontrar el porvenir del grito ancestral marcado en las dificultades que presenta la existencia del ser. Cabe agregar que el ser humano siempre está más adelante que su propio proyecto y busca un porvenir bajo la responsabilidad de su pasión.

El existencialista no cree en el poder de la pasión. No pensará nunca que una bella pasión es un torrente devastador que conduce fatalmente al hombre a ciertos actos y que, por tanto, es una excusa; piensa que el hombre es responsable de su pasión. El existencialista tampoco pensará que el hombre puede encontrar socorro en un signo dado en la tierra, que lo orientará, porque piensa que el hombre descifra por sí mismo el signo como prefiere. Piensa, pues, que el hombre, sin ningún apoyo ni socorro, está condenado a cada instante a inventar al hombre. Ponge, citado por Sartre, ha dicho: "El hombre es el porvenir del hombre". 28

Este aforismo de "inventar al hombre" es el que le da la profundidad a la marcha conceptual latinoamericana e indigenista; hay que investigar nuevas posibilidades, nuevos conocimientos y nuevas alternativas, para poder relacionar lo vetusto con la proyección filosófica del nuevo acontecer existencial de libertad. En otro orden cosas, el ser humano con tendencia latinoamericana no puede estar por debajo de la sociedad; el otro que soy yo para el mundo no es un proyecto acabado, por el contrario, es la existencia del nuevo amanecer, con pensamiento crítico y autónomo frente al mundo que observa y dirime frente a ese ego que está en el ser; en efecto, está condenado a ser libre y responsable de sus decisiones. La libertad está en el centro del ser humano cuando existe el compromiso, la responsabilidad y la justicia; es la trayectoria existencial que invade la profundidad de la identidad para desenrollar puñados de avidez cultural, patrimonial y regional en un contexto determinado; el ser humano es el constructor de su propia vida y pensamiento, él se hace; no es él, es él en medio de un cúmulo de actuaciones sensatas, vivencias cotidianas, reflexiones culturales y pensamientos ancestrales, en que se refleja su desenvolvimiento existencial latinoamericano hacia diferentes partes del mundo; él es el producto acabado para su porvenir.

El hombre, tal como lo concibe el existencialista, si no es definible, es porque empieza por no ser nada. Solo será después, y será tal como se haya hecho. Así pues, no hay naturaleza humana, porque no hay Dios para concebirla.

El hombre es el único que no solo es tal como él se concibe, sino tal como él se quiere, y como se concibe después de la existencia, como él se quiere después de este impulso hacia la existencia; el hombre no es otra cosa que lo que él se hace. Este es el primer principio del existencialismo. ${ }^{29}$

El existencialismo que ve al ser humano dotado de una fuerza hacia su propio impulso para hacerse a sí mismo es uno de los primeros pasos desde Sartre para encontrar la identidad latinoamericana a partir de la interdependencia cultural, y así lograr una estructura de pensamiento autónomo, libre y sin zozobra. El hombre que se apropia de la identidad cultural indigenista latinoamericana es el que va a

28 Sartre, El existencialismo es un humanismo, 43-44.

29 Sartre, El existencialismo es un humanismo, 31. 
alcanzar la libertad, y dicha libertad, como se mencionó, ocasiona angustia en medio de una pasión que es el reflejo de la tenacidad del pensamiento en el encuentro con su ego interdisciplinar; por tanto, estos hechos producen sensibilidad frente a un contexto determinado. Como puede observarse, la angustia tiene una dimensión ontológica porque es la expresión de nuestra libertad, modo de ser y modo de existir. Cuando se asume la identidad en medio de la libertad, la angustia se comporta como una ética en que el ser humano se vuelve responsable por sus actos, se vuelve responsable a sí mismo, por medio de su naturaleza humana; la libertad es un acto universal. "El hombre es poseedor de la naturaleza humana; esta naturaleza humana, que es el concepto humano, se encuentra en todos los hombres, lo que significa que cada hombre es un ejemplo particular, de un concepto universal, el hombre". ${ }^{30}$

Según se ha citado, para Sartre el ser humano es el concepto particular en la universalidad del mundo donde debe adquirir, a partir de su ser y quehacer, el sentido de la responsabilidad para eslabonar un sentido lógico de convivencia dentro de su hábitat definido. Cuando se hace responsable, se entra en angustia y, al mismo tiempo, cae en la profundidad de los problemas cotidianos; y, en este propósito, el eslabón que elegimos es la búsqueda del bien; si es bueno para un único ser, es bueno para todos los que conforman ese hábitat llamado América Latina.

En efecto, no hay ninguno de nuestros actos que, al crear al hombre que queremos ser, no cree al mismo tiempo una imagen del hombre, tal como consideramos que debe ser. Elegir ser esto o aquello es afirmar al mismo tiempo el valor de lo que elegimos, porque nunca podemos elegir el mal; lo que elegimos es siempre el bien, y nada puede ser bueno para nosotros sin serlo para todos. ${ }^{31}$

Sobre la base de las consideraciones anteriores, estos cuestionamientos del ser humano frente a su elección son una particularidad que se debe afrontar para desentrañar lo más profundo del ser; si se elige el mal, que es una tentativa que marca el fracaso de la libertad por intermedio de acciones contrarias a los principios de la alteridad y la cohesión con el otro, entonces forjará episodios lascivos que de antemano serán una escoria para su propia identidad; y en América Latina que, por sus múltiples necesidades cae en estos graves hechos de vida, tendrá lugar un episodio triste, que lo aleja y lo pone en lo más profundo del abismo, en un camino sin salida. El otro ya no es el otro; en contraste, ese otro se convierte en un objeto, en una cosa, en un sinsentido, con aplazamiento y desventura del sentimiento, la mansedumbre y la bondad.

Siendo el mal un abatimiento del bien, queda en entredicho el oleaje de las circunstancias que incitan al ser humano a realizar el mal, en que el hombre es un torturador para el mismo hombre. Lo negativo, lo oscuro o lo malo son una connotación que está presente y queda a libre arbitrio si se toma o se deja; y si la persona, sin sentido de la vida, toma caminos equivocados que, en lugar de brindarle un equilibrio, encuentra ante todo un desequilibrio, con consecuencias intrínsecas profundas, observará que servirse del otro por medio de la mentira o el engaño acarrea circunstancias de vida paupérrimas e indignantes frente a su formación existencial.

Por eso, contrario a estos planteamientos, cuando se elige el bien, se encuentra que en la filosofía la consciencia de sí desde la contemplación hasta la práctica toma momentos de reflexión e inflexión en la

30 Sartre, El existencialismo es un humanismo, 16.

31 Sartre, El existencialismo es un humanismo, 34. 
cotidianidad; la verdadera esencia del ser humano es su propia existencia, elegir un camino es elegir un valor y ser libres tanto para sí como para el otro es ya un punto benéfico para un desarrollo potencial en la sociedad.

Así, el primer paso del existencialismo es poner a todo hombre en posesión de lo que es, y hacer recaer sobre él la responsabilidad total de su existencia. Y "cuando decimos que el hombre es responsable de sí mismo, no queremos decir que el hombre es responsable de su estricta individualidad, sino que es responsable de todos los hombres". ${ }^{32}$ En el sentido de la vida marcado en un singular existencialismo latinoamericano, en que el ser humano con ideología innata bajo parámetros indigenistas y, por supuesto, acarreando sobre sus hombros la responsabilidad de lo que es, se vuelve significativo realizar un eco a la realidad mestiza; ser latinoamericano implica el resultado de una raza, sus costumbres, su cultura, sus tradiciones y pensamientos inmersos dentro del territorio.

Los ancestros han enseñado que entre sus comunidades debe primar la comunidad, la colectividad; en palabras de Sartre, la responsabilidad del hombre no es individual, sino que aplica a todos los que pertenecen a una colectividad; entonces, es atinado, desde lo ancestral, hablar de comunidad en pro del otro. Para ello, se reúnen, trabajan, disfrutan y practican conocimientos propios de su región, establecen un diálogo con el que necesita resolver un problema, practican el rito del yagé, en fin, todo está condicionado bajo el amparo de la comunidad. Estas tradiciones y relaciones sociales adquieren fundamento en una filosofía propia cuando, al preocuparse por el otro, el amor adquiere un sentido comunitario. "Ahora bien, en realidad, para el existencialismo, no hay otro amor que el que se constituye; no hay otra posibilidad de amor que la que se manifiesta en el amor" ${ }^{33}$ En efecto, el amor es la manifestación desinteresada para darse al otro en relación con el ser.

Bajo este entendimiento, ser latinoamericano implica pensamiento, individualidad, colectividad, persona y, más aún, si efectivamente analizamos las culturas indígenas que, como parte de un universo cambiante, lleno de mezquindad en su ego y que materialmente por ley natural conlleva la desintegración, especie que se encuentra en un no ser, de igual forma presta atención a la universalidad de la persona; existir con una existencia espiritual en que su profundidad radica en las más excelsas dimensiones del ser que fundamentan angustia existencial. Ser indígena implica todos los apelativos posibles en el marco conceptual y saber ancestral, sin importar que para algunos es intempestivo, en el conocimiento occidental, enraizar pensamiento propios o autóctonos; ello nace de la persona y no del individuo.

\section{Los coreguajes y el campo fenomenológico en la ciencia}

La fenomenología en su proceso histórico es un entramado filosófico que se ha desarrollado en diferentes facetas de la cotidianidad del ser humano; para esta, la persona es la única que tiene la dignidad absoluta en la sociedad a través de la reflexión y la consciencia de sí; tales actitudes fenomenológicas se dan bajo dos reducciones: la iedética (vivencia-intencionalidad) y la trascendentalidad; en otras palabras, se engendra una psicología de hecho, en que el ser humano es el artífice de su propia realidad. Ella (la fenomenología) surge debido a la existencia de las guerras que han aquejado al hombre en todo su existir,

32 Sartre, El existencialismo es un humanismo, 33.

33 Sartre, El existencialismo es un humanismo, 57. 
debido a un personalismo que trata de dar respuesta a la posguerra y, de igual forma, por el avance de la ciencia que crea diferentes problemas en la vivencia ética del hombre.

Así, en este sentido, la fenomenología aparece cuando el ser humano se empieza a preocupar por su mismo ser, por su propio ser en el mundo donde habita; esto es, no apunta a un lenguaje científico, sino más bien a un lenguaje que día a día vive en su experiencia vivencial, tanto personal como colectiva. Somos, en esencia, seres pensantes y esa es la razón de ser del acontecimiento fenoménico.

Entendido así, Husserl, uno de los máximos expositores de la fenomenología, afirma con todo rigor y carácter que esta disciplina en la filosofía se entiende y se comprende mediante las justificaciones intelectuales; en esta dirección, "hasta que el sentido dependa del sentido, la esencia de la esencia, y así, solo una fenomenología completa, desarrollándose omnilateralmente, será la fuente de todas las intelecciones completas, de todas las justificaciones omnilaterales y últimas"; ${ }^{34}$ solo así se puede encontrar el sentido estricto de la intelección humana mediante una reflexión filosófica que acerca los conceptos más abstractos y más concretos.

Los fenómenos que ocurren a lo largo del acontecer existencial del hombre son los que, por ende, atraviesan el ser del ser, en medio de un mundo y un hábitat definido. Una experiencia vivencial y trascendental la encontramos en diferentes culturas del mundo y ellas, en medio de sus tradiciones y creencias, han elaborado contextos que hacen de su cultura una máxima intelección en la sociedad que, por excelencia, forma una pluriculturalidad.

Desde esta perspectiva, y en consonancia con los anteriores planteamientos, resulta oportuno indagar y reflexionar a partir del acontecer existencial del ser humano el andamiaje que aborda el pensamiento, el sentimiento, la tradición, los ritos y la cultura de la etnia coreguaje en Colombia y, más exactamente, en el Caquetá, territorio de la Amazonía, que es donde habita este grupo indígena. Sus arraigos experienciales y vivenciales han sido desarrollados a lo largo de una posición férrea y consecuente con su lineamiento ancestral y geográfico; son ellos los que, por esencia propia, han construido un mundo tradicional fenoménico en su saber cultural.

Sobre la base de las consideraciones anteriores, se observa que la etnia coreguaje fortalece sus principios y consideraciones en una autenticidad propia; una autenticidad que no se ha dejado contagiar por el saber colono occidental; en sí, su gama ancestral es propia y hace de ellos un grupo idóneo entre las culturas indígenas de América Latina. Indagar sus creencias, ritos, costumbres y espiritualidad, en relación con la cosmología de la selva es encontrar un saber auténtico que, desde su contexto propio, fecunda el saber tradicional.

Lo auténtico es la meta que la razón finalmente puede alcanzar, incluso en su modo caído sinrazón. Es lo que, según Husserl, "no se acierta" ${ }^{35}$ en la oscuridad y en la confusión; lo que, en cambio, se alcanza en la claridad del fin y del camino, y en las formas esenciales propias de esa claridad.

34 Edmund Husserl, Las conferencias de Londres: Método y filosofía fenomenológicos (Madrid: Sígueme, 2021 ), 21.

35 Edmund Husserl, Lógica formal y trascendental: Ensayo de una crítica de la razón lógica ( México: Universidad Nacional Autónoma de México, 1962), 57. 
La razón de ser de la etnia coreguaje en su pensamiento propio es el armazón idóneo y coherente frente a sus reflexiones ancestrales. Para Occidente, muchos de sus planteamientos son la sinrazón de la razón de su acontecer existencial; estas conjeturas apriorísticas se dan al no acceder de manera propia y auténtica frente a su legado claro y autóctono de lo que, en realidad, genera su pensamiento.

La ciencia, fruto de investigaciones exhaustivas que conllevan generar conocimiento en un círculo académico produce con el tiempo un espectro que a lo largo de los días y con rasgos lógicos y fundamentales sobrepasan los límites de lo que el ser humano podría realizar desde un punto de vista artesanal y expectante. Los apegos a lo sofisticado, tecnológico y tecnócrata han hecho reflexionar y pensar que uno de los puntos fundamentales desde un humanismo bien entendido es volver a lo natural, al encuentro con el otro a través de la forma más consecuente, espiritual y relacional; solo los equipamientos de los saberes propios de la naturaleza hacen del ser humano una persona libre y autónoma respecto del contexto propio, regalo de la fraternidad de la selva amazónica.

El naturalismo es una consecuencia del descubrimiento de la naturaleza, considerada unidad del ser espaciotemporal conforme a las leyes naturales exactas. Con la realización progresiva de esta idea en las sucesivas ciencias de la naturaleza que acogen un gran número de conocimientos estrictos, el naturalismo se propaga cada día más. De un modo análogo, el historicismo se desarrolló más tarde como una consecuencia del descubrimiento de la historia y de la fundación de las sucesivas ciencias del espíritu. Siguiendo los hábitos de interpretación dominantes en cada uno, "el naturalista tiende a encararlo todo como naturaleza; el que se dedica a las ciencias del espíritu tiende a encararlo como espíritu, como creación histórica y, por consiguiente, ambos tienden a falsear el sentido de aquello que no puede ser encarado a su modo" ${ }^{36}$

Husserl deja entrever que la ciencia de la naturaleza ocupa un lugar relevante en el conocimiento, y no reconocerlo sería un error, ya que su comportamiento intelectivo es el acontecer organizado de las ideas, que funda un conocimiento naturalista. En efecto, en la cultura coreguaje, lo natural es una adhesión a las costumbres, saberes y tradiciones que la selva amazónica les proporciona, para desarrollar toda una gama de conocimientos que ocupan el epicentro de sus organizaciones familiares y colectivas. Sin embargo, su carácter y exposición chamánica han creado un sesgo particular, en que las personas más adelantadas pueden tener acceso al conocimiento de los ancestros. Por su parte, su cosmología es un bastidor muy relevante en la convicción conceptual que ellos manejan como acontecer intelectivo e investigativo, ya que el asombro, la pregunta y el cuestionamiento han llevado al indígena coreguaje a identificar su propio orbe como una insignia personal y comunitaria en el conocimiento naturalista de la existencia de mundo.

En otro orden cosas, Husserl, citado en García Ruiz, afirma:

El mundo no es para mí, en general, nada más que el que en tales cogitaciones existe conscientemente y vale para mí. Exclusivamente por tales cogitaciones tiene el mundo todo su sentido y su validez de ser. En ellas transcurre toda mi vida mundana. Yo no puedo ponerme a vivir, a experimentar, a pensar, a valorar y actuar, dentro de ningún otro mundo que no tenga en mí y por mí mismo, sentido y validez. ${ }^{37}$

36 Edmund Husserl, La filosofía como ciencia estricta: Filosofía naturalista (Buenos Aires: Terramar, 2007), 1.

37 Pedro Enrique García Ruiz, “¿Una fenomenología no intencional? Lévinas, Henry yla idea de una 'post-fenomenología”, Revista Filosofía UIS 7, n. ${ }^{\circ}$ (2008): 186. https://revistas.uis.edu.co/index.php/revistafilosofiauis/article/view/149. 
Como se puede observar, Husserl alimenta la palabra mundo con su propio acontecer existencial y su propia validez, que descubre por mediación del conocimiento que organiza su propio valor y rigidez en el mundo donde existe; y es ahí donde la vedada connotación de mundo adquiere el sentido de su propia razón explicativa de este.

Para la etnia coreguaje, la palabra mundo es signo de belleza, armonía, equilibrio psíquico y emocional; en él encuentran la sabiduría que necesitan para desentrañar su arjé latente en sus convicciones ancestrales. La cosmovisión entre los coreguaje, que es transmitida con la ayuda de la oralidad, es un aspecto interesante entre sus creencias, ya que estos saberes ancestrales son los que delimitan su posición frente a la naturaleza. Para ellos, la naturaleza es un todo frente al hombre; ella es la que guía para continuar como pueblo, ella es la madre que da la vida. Según su cosmovisión, el mundo posee tres niveles: el chejaboebü, que es la tierra de abajo, es el nivel donde habitan las personas y poseen la relación directa con la naturaleza, el viento, el agua, el trueno, la luna y el sol; el chejasanaba, que es la tierra del centro, donde se encuentra el aire, es un lugar propio de los sabedores o chamanes, y, por último, se encuentra el chejasesebü, que es la tierra de los astros y las estrellas, donde no hay seres humanos.

Estos antecedentes, que revitalizan la etnia coreguaje, son el punto de partida para realizar un diálogo epistemológico, punto focal para interpretar esta realidad ancestral mediante la reflexión y disertación de pensadores que, a través de posiciones éticas y políticas, marcan un vestigio en la filosofía.

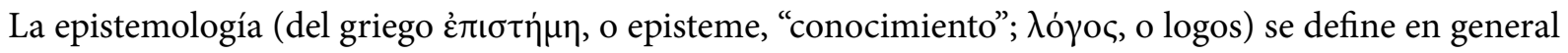
como el estudio de la producción y validación del conocimiento científico (racional, metódico). Se ocupa de problemas tales como las circunstancias históricas, psicológicas y sociológicas que llevan a su obtención, y los criterios por los cuales se la justifica o invalida. Es conocida como

la rama mayor de las Ciencias. Desde la filosofía, la epistemología es la rama que trata de los problemas filosóficos que rodean la teoría del conocimiento; se ocupa de la definición del saber y de los conceptos relacionados, de las fuentes, los criterios, los tipos de conocimiento posible y el grado con el que cada uno resulta cierto, así como la relación exacta entre el que conoce y el objeto conocido. ${ }^{38}$

Tales postulados son los que enmarcan la esencia para dialogar con el saber ancestral coreguaje en su cosmovisión propia, autóctona y original. Las preocupaciones epistemológicas en la historia de la filosofía, y tomando como referente el problema de la cosmovisión, han implementado categorías importantes para descifrar el problema del mundo. Desde la filosofía, observamos que diferentes pensadores han realizado e indagado acercamientos en referencia al mundo: ¿de dónde viene? o ¿cuál es el origen? Son los interrogantes que han estado presentes en la filosofía y, en este sentido, su itinerario epistemológico ha suscitado respuestas que han marcado la existencia del ser humano para organizar ideas propias en una estructura de pensamiento.

38 Orlando Enar David Solarte, "El papel de la epistemología en la formación académica”, Revista UNIMAR 34, n. 2 (2016): 63. http://editorial.umariana.edu.co/revistas/index.php/unimar/article/view/1241. 


\section{Conclusiones}

La humanidad está imbuida de una serie de acontecimientos que el mismo ser humano desconoce; no somos producto de un devenir a priori, es decir, desconocimiento de nuestro legado ancestral. Cada miembro de una comunidad posee una serie de definiciones que lo hacen propio, auténtico, diferente; latinoamericanos que desde siglos han desconocido el legado indígena y, por qué no, el pensamiento de nuestros aborígenes. El saber de nuestros mayores es ese itinerario existencial que manifiesta sabiduría y elongación de la palabra, que hace de su actuar un sentir idóneo, profundo y latinoamericano; yo no puedo negar mis abolengos; soy fruto de un entramado cultural indígena que se manifiesta en el diario vivir; yo no puedo ser la negación de mí mismo; al negar al otro que está a mi lado en un inconsciente pluricultural y regio cuando es necesario, yo soy el producto de ese inconsciente que por más que lo aleje se manifiesta en el hecho de una sabiduría profana para algunos y necesaria para otros.

La pachamama, el cosmos y la naturaleza, eslabones donde los mayores emergen una epistemología silenciosa y omnisciente, son el eco que retumba el sentir de un verdadero y auténtico latinoamericano; sería el prototipo que debe organizar la ansiedad del otro yo, en cuestionamientos de resarcir un pasado que en su momento pudo ser promisorio, pero que, con el tiempo, la inequidad, la desigualdad, el menosprecio por el otro, la autosuficiencia y la corrupción, han hecho de una generación la contradicción y el antagonismo que pulula en la sociedad actual. Mi yo y el otro yo son los escenarios materiales diferentes del ser trascendente; mi mismo "yo" es un "yo" corpóreo, que incluye la materia, y no es un sujeto espiritual o puramente inmaterial. El yo es la imagen hacia el otro que necesita comprender, entender y asimilar el proyecto ancestral de la templanza latinoamericana; debo aprehender del yo de mis antepasados para forjar un pensamiento autónomo y libre, de vientos frescos, obnubilados por el placer que genera la selva virgen con todos sus artefactos naturales, diversos, propios, en medio de un mundo que no ve en ella la salvación de la vida, sino que, por el contrario, desea acabar, exterminar y desolar el producto que en su bondad infinita nos brinda.

\section{Bibliografía}

David Solarte, Orlando Enar. "El papel de la epistemología en la formación académica". Revista UNIMAR 34, n. 2 (2016): 63-67. http://editorial.umariana.edu.co/revistas/index.php/unimar/article/view/1241.

Díaz, Arturo. "La concepción de la persona en Jacques Maritain: Desde la noción de individuo a la de libertad personal". Polis: Revista Latinoamericana 15 (2006): 1-13. https://journals.openedition.org/polis/4874.

Flores, Gabriela. "La muerte desde Lévinas". Alpexistencial. Acceso el 31 de octubre de 2021. https://www. alpexistencial.com/post/la-muerte-desde-lévinas.

García Ruiz, Pedro Enrique. ¿Una fenomenología no intencional? Lévinas, Henry y la idea de una 'postfenomenología"'. Revista Filosofía UIS 7, n. ${ }^{\circ} 1$ (2008): 185-95. https://revistas.uis.edu.co/index.php/ revistafilosofiauis/article/view/149.

Geertz, Clifford. La interpretación de las culturas. Barcelona: Gedisa, 1987.

Giménez Giubbani, Analía. “Emmanuel Lévinas: Humanismo del rostro”. Escritos 19, n.o 43 (2011): 337-349.

Husserl, Edmund. La filosofía como ciencia estricta: Filosofía naturalista. Buenos Aires: Terramar, 2007.

Husserl, Edmund. Las conferencias de Londres: Método y filosofía fenomenológicos. Madrid: Sígueme, 2021.

Husserl, Edmund. Lógica formal y trascendental: Ensayo de una crítica de la razón lógica. México: Universidad Nacional Autónoma de México, 1962.

Jiménez, Margarita. Tradiciones coreguaje. Quito: Abya-Yala, 1989. 
Lévinas, Emmanuel. Más allá del versículo: Lecturas y discursos talmúdicos. Buenos Aires: Lilmod, 2006.

Lévinas, Emmanuel. Totalidad e infinito: Ensayo sobre la exterioridad. Madrid: Sígueme, 1977.

Marion, Jean-Luc. Siendo dado: Ensayo para una fenomenología de la donación. Madrid: Síntesis, 2008.

Ministerio de Cultura. "Caracterizaciones de los Pueblos Indígenas en Riesgo". Acceso el 31 de octubre de 2021. https://www.mincultura.gov.co/areas/poblaciones/pueblos-indigenas/Documents/Compilado\%20de\%20 Caracterizaciones\%20Pueblos\%20en\%20Riesgo.pdf.

Ministerio de Cultura. "Caracterizaciones de los pueblos indígenas de Colombia". Acceso el 31 de octubre de 2021. https://www.mincultura.gov.co/prensa/noticias/Documents/Poblaciones/PUEBLO\%20KOREGUAJE.pdf.

Morales Escobar, Paola Inés. "Comunicación y cultura en la selva: La comunidad coreguaje". Tesis de grado. Pontificia Universidad Javeriana, 2008. https://repository.javeriana.edu.co/bitstream/handle/10554/5330/ tesis315.pdf? sequence $=3$.

Prada, Edilma. "Coreguaje: Voces del despojo". En Memorias: 12 historias que nos deja la guerra, 173-93. Konrad Adenauer Stiftung, 2017. http://consejoderedaccion.org/webs/memorias12historias/.

Romero López, Andrés y Ángela Patricia Muñoz. Caracterización pueblo indígena coreguaje. Bogotá: Procuraduría General de la Nación, 2019. https://www.procuraduria.gov.co/portal/media/file/Caracterizacion\%20Coreguaje. pdf.

Sabino, Carlos. El proceso de investigación. Buenos Aires: El Cid, 1976.

Sartre, Jean-Paul. El existencialismo es un humanismo. Traducido por Victoria Prati. Barcelona: Edhasa, 1973.

Valle, José Miguel. "Yo soy tú, cuando yo soy yo". Espacio Suma NO Cero. Acceso el 31 de octubre de 2021. https:// espaciosumanocero.blogspot.com/2020/04/yo-soy-tu-cuando-yo-soy-yo.html. 